\title{
Systematic review and meta-analysis of welding procedures in one-piece cast implant-supported frameworks
}

\author{
Jéssica Marcela de Luna \\ GOMES(a) \\ Sandra Lúcia Dantas de \\ MORAES(b) $^{(10}$ \\ Cleidiel Aparecido Araujo \\ $\operatorname{LEMOS}^{(a)}$ \\ Ronaldo Silva CRUZ(a) \\ Hiskell Francine Fernandes e \\ OLIVEIRA $^{(a)}$ \\ Eduardo Piza PELlizZER ${ }^{(a)}$ \\ (a) Universidade Estadual Paulista - Unesp, \\ Araçatuba Dental School, Department \\ of Dental Materials and Prosthodontics, \\ Araçatuba, SP, Brazil. \\ (b) Universidade de Pernambuco - UPE, Faculty \\ of Dentistry, Camaragibe, PE, Brazil.
}

Declaration of Interests: The authors certify that they have no commercial or associative interest that represents a conflict of interest in connection with the manuscript.

Corresponding Author:

Eduardo Piza Pellizzer

E-mail: ed.pl@uol.com.br

Submitted: September 9, 2019

Accepted for publication: October 10, 2018

Last revision: October 16, 2019

\begin{abstract}
The objective of this systematic review and meta-analysis was to evaluate the effect of welding techniques on implant-supported prostheses and determine whether they contribute to a better adaptation compared with a one-piece cast. A search was conducted using the PubMed/MEDLINE, Embase, and Cochrane Library databases, and articles published until November 2017 were obtained from these databases. This review followed the PRISMA criteria and is registered on the PROSPERO platform (CRD42017081865). The PICO question was "Do welding procedures in one-piece cast implant-supported frameworks influence implant/abutment-framework marginal misfits?" Eleven studies were selected for a qualitative analysis, and seven studies were selected for a quantitative analysis. A total of 189 specimens were fabricated using different materials (cp-Ti, Ni-Cr, $\mathrm{Cr}-\mathrm{Co}$, and noble alloys), and welding techniques such as laser welding, conventional welding, tungsten inert gas, and brazing were applied. A vertical marginal misfit was measured using an optical microscope, a stereomicroscope, and/or a scanning electron microscopy. The qualitative analysis in the studies demonstrated a positive effect of the welding techniques on the adaptation of the infrastructures. The meta-analysis confirmed the results ( $p<0.00001$; MD: -36.14 ; 95\%CI: -48.69 to -23.59 ). Within the limitations of this study and regarding the heterogeneity of the samples, we conclude that the soldering point technique is effective for obtaining relatively low values of marginal misfit, with laser welding as the most effective technique. However, additional studies were recommended due to the heterogeneity of different variables (alloys, connection, and misfit evaluation) in the included studies.
\end{abstract}

Keywords: Dental Implants; Welding.

\section{Introduction}

The accuracy of fitting between a prosthesis and an implant is a prerequisite for the long-term success of implant-supported rehabilitations. ${ }^{1}$ Misfits formed at the interface between the implant and the infrastructure transfer stresses to the prosthesis and the peri-implant bone, with consequent adverse biological responses and prosthetic complications. ${ }^{2,3}$

Several fabrication methods of implant frameworks are proposed to minimize distortion, and they consequently reduce the marginal misfit. ${ }^{4}$ 
However, studies affirm that distortion is inevitable during the fabrication process of frameworks (stone cast, inclusion in coating material, and casting in metallic alloy) since it is inherent to the process. ${ }^{5,6,7}$ New technologies, such as CAD/CAM systems, demonstrate substantial accuracy of the pieces that constitute the infrastructure in a one-piece cast, ${ }^{8,9}$ and certain manufacturing stages are omitted compared with the conventional technique of lost-wax. ${ }^{3}$

A frequently employed procedure to reduce the framework distortion, which is known as a soldering point, is sectioning with subsequent welding. This procedure was proposed in 1987 as an alternative method for frameworks that were manufactured in a one-piece cast to promote better adaptation between the prosthesis and the implant, ${ }_{10}^{10}$ which would reduce the residual stress exerted on the prosthesis and the bone. ${ }^{11}$ Different welding techniques are applied, such as conventional welding ${ }^{12}$ gas-torch brazing, laser welding, and tungsten inert gas (TIG). ${ }^{13}$

Welding is the sectioning and fixation of the parts to be soldered with acrylic resin for the previous one-piece framework; inclusion in the coating set is necessary and enables the removal of acrylic resin and the release of the space to be welded. A gas-torch brazing technique is performed by a metal alloy with a melting point that is lower than that of the base metal at temperatures above $450^{\circ} \mathrm{C}$; the addition of molten material supplied by the flame contacts the areas to be welded, which causes their union. ${ }^{14,15,16}$

The tungsten inert gas (TIG) technique enables parts to be bonded by heating the materials through an arc between the non-consumable tungsten electrode and the part. However, the laser welding technique commonly uses a mixture of gas that contains $\mathrm{CO} 2$ and yttrium aluminum garnet (YAG) in the solid state. Energy is supplied in the form of an electromagnetic wave that melts the surface that receives the impact, removes a small amount of metal and transfers it to the other surface. Because the energy is applied with substantial force in the region, the use of welding coating is not needed in the laser process, which enables the welding of structures or parts with aesthetic finishes without damaging them. ${ }^{14,15,16}$

Certain studies ${ }^{6,17,18}$ affirm that the implementation of a welding technique in an implant-supported framework can reduce misfit between an implant and a prosthesis. However, different studies report the absence of an effect, ${ }^{11}$ even a negative effect, ${ }^{12}$ on marginal misfit when using the soldering point technique. Therefore, no consensus has been reached regarding a technique that exhibits the best adaptation values.

Thus, this systematic review of the literature intends to evaluate whether the welding technique produces a better adaptation of prosthetic infrastructures than infrastructures manufactured in a one-piece cast. The null hypothesis affirms that no difference exists between two pieces manufactured in a one-piece cast, regarding the marginal misfit, when compared with welding techniques.

\section{Methodology}

\section{Protocol register}

This systematic review follows the PRISMA criteria $^{20}$ in accordance with certain systematic reviews of the literature. ${ }^{21,22}$ In addition, the methods applied to conduct the review were recorded on the Prospero registration platform (Prospective Register of Systematic Reviews) (CRD42017081865).

\section{Eligibility criteria}

The studies eligible for this systematic review followed the criteria: a) Clinical studies (controlled, randomized, prospective, and/or retrospective studies); b) in vitro studies; c) studies that evaluate the vertical marginal misfit; and d) studies published in English.

The exclusion criteria of the studies are listed as follows: a) Clinical cases; b) cases of series; c) in vivo studies (animals); and d) reviews.

The formulated PICO question was "Do welding procedures in one-piece cast implant-supported frameworks influence implant/abutment-framework marginal misfits?" The population was composed of three-element implant-supported frameworks/or prostheses. Intervention was the realization of the soldering point technique. The comparison consisted of the confection of one-piece casts of implant-supported frameworks/or prostheses. The outcome was evaluated considering the influence of the two techniques in 
relation to the vertical $(\mu \mathrm{m})$ marginal misfit of the implant/abutment frameworks.

\section{Search strategy}

An electronic search was conducted by two independent researchers (J.M.L.G and C.A.A.L) using PubMed/MEDLINE, Embase, and Cochrane Library databases to obtain articles published until October 2017 following the eligibility criteria. The following keywords were employed: "soldering and implant supported prostheses OR soldering and framework OR soldering and misfit $O R$ soldering and fit $O R$ soldering and adaptation OR welding and implant supported prostheses OR welding and framework OR welding and misfit OR welding and fit $O R$ welding and adaptation OR one piece cast and implant supported prostheses OR one piece cast and framework OR one piece cast and fit OR one piece cast and misfit OR one piece cast and adaptation".

In addition, manual searches of the following journals were conducted with a significant concentration in the area of prosthodontics and implantology: International Journal of Prosthodontics, Journal of Prosthetic Dentistry, Clinical Implant Dentistry and Related Research, Clinical Oral Implants Research, International Journal of Oral and Maxillofacial Implants, International Journal of Oral and Maxillofacial Surgery, Journal of Oral and Maxillofacial Surgery, Journal of Clinical Periodontology, Journal of Dental Research, Journal of Oral Implantology, Journal of Oral Rehabilitation, Journal of Periodontology, and Periodontology 2000, International Journal of Periodontics and Restorative Dentistry, European Journal of Esthetic Dentistry, and Journal of Prosthodontics.

During the selection process, studies were conducted to verify whether the information in the title and abstract comply with the eligibility criteria. When the first two researchers disagreed, a third researcher (E.P.P) was consulted, and an agreement was obtained via a consensus meeting.

\section{Data analysis}

One author (J.M.L.G) was responsible for collecting relevant information from the included articles, and a second author (C.A.A.L) reviewed all collected information. The data collected from the selected articles consisted of information about the author, study year, study type, number of samples, materials, type of prosthesis, implant system or abutment, welding technique, measurement method, vertical marginal misfit (average/standard deviation) for each evaluated group (one-piece cast and soldering point), conclusions, and effect of welding techniques (negative/none/positive) will be considered for a qualitative analysis.

\section{Risk of bias}

The risk of bias for the studies was analyzed using the JBI Critical Appraisal Checklist for Quasi-Experimental Studies (non-randomized experimental studies). JBI provides a critical analysis of the methodological quality of the selected studies. These tools are built into the first JBI System for management, evaluation, and a unified information verification software module (SUMARI; http://joannabriggs.org/sumari.html ${ }^{23}$. Each study is individually evaluated. JBI provides ten items to be selected based on the characteristics of the studies as follows: "Yes," "No," "Not clear," or "Not applicable". The analysis is conducted via two examiners, and subsequently, a union score of all studies is obtained.

\section{Summary measurements}

One researcher (J.M.L.G.) collected relevant data from the articles, which were checked by two other researchers (R.S.C. and H.F.F.O). The meta-analysis was based on an inverse variance (IV) method. A marginal misfit was considered to be the continuous outcome and was evaluated using the mean difference (MD) evaluated by IV with a 95\% confidence interval (CI). The MD values were considered significant when $p<0.05$. For statistically significant $(p<0.10)$ heterogeneity, a random-effects model was used to assess the significance of the treatment effects. When statistically significant heterogeneity was not observed, an analysis was performed using a fixed-effects model. The software Reviewer Manager 5 (Cochrane Group) was used for the meta-analyses.

\section{Additional analysis}

The Kappa score was used to calculate the interreader agreement during the inclusion process for publication-evaluated databases. Any disagreements were resolved via discussion and consensus among all authors. 


\section{Results}

\section{Search strategy}

The database search selected 1164 studies, including 593 studies in PubMed/MEDLINE, 515 studies in Embase, and 56 studies in the Cochrane Library. All duplicate references were excluded; a total of 1086 articles were selected for the evaluation of titles and abstracts. After a detailed reading of the titles and abstracts and application of the eligibility and exclusion criteria, a total of 27 articles were selected for reading. After reading the articles, 15 articles $^{14,13,1,10,27,28,29,30,31,32,33,34,35,36,37}$ were excluded due to the reasons listed in Table 1. Thus, 11 articles were included to analyze the results ${ }^{2,5-7,11,12,17,18,23,24,25}$, and 7 studies were selected for a quantitative analysis. $5,6,7,17,23,24,25$ Details regarding the search strategy are exemplified in Figure 1. In relation to the inter-reader test, a high degree of agreement among the researchers was observed: PubMed/MEDLINE (kappa=0.87), Embase (kappa $=0.90)$, and Cochrane Library $(k a p p a=1) \cdot{ }^{38}$

\section{Study characteristics}

\section{Samples, frameworks, and implants}

The characteristics of the included studies are listed in Table 2. A total of 11 studies published between 1996

Table 1. Studies excluded and the reasons for exclusion.

\begin{tabular}{|c|c|}
\hline Reasons for Exclusion & References \\
\hline Insufficient data & Clelland, 199624; Zervas, 199925; Lencioni, $2015^{4}$ \\
\hline Overdenture and full arch & 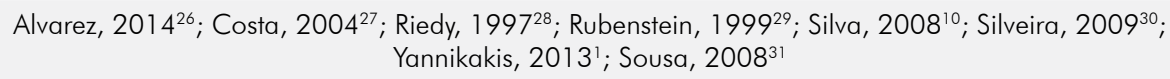 \\
\hline Studies without comparative group & Barbi, $2012^{13}$ \\
\hline Fixed partial denture on teeth & Byrne, $1992^{32}$; Jei, $2014^{33}$ \\
\hline Clinic cases & Evans, $1997^{34}$ \\
\hline
\end{tabular}

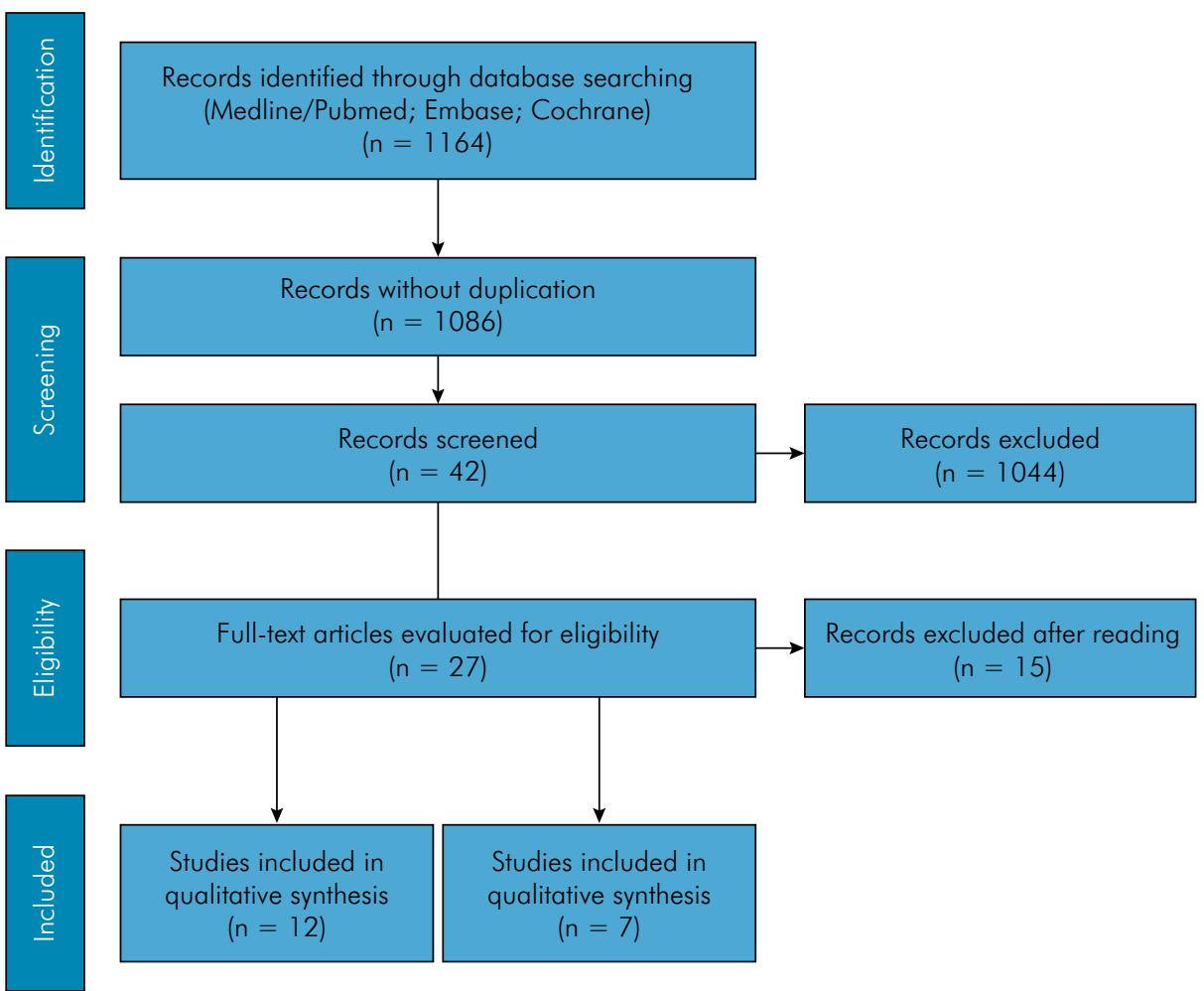

Figure 1. Flowchart detailing the search strategy. 
and 2017 were selected. ${ }^{2,5,6,7,11,12,17,18,23,24,25}$ All selected studies were considered in vitro, with an evaluation of fixed prostheses that were implant-supported. The studies presented a total of 189 samples (range 3 to 20 samples per group). Nine $5^{5,67,11,17,18,23,24,25}$ of the included studies discussed the measurements of misfit on the interface between the framework and the abutment, and two studies ${ }^{1,12}$ discussed the measurements of misfit on the interface between the implant and the frameworks (do not use abutments). Frameworks were constructed using several materials: cp-Ti, 5,6,11,17, 23,25 $\mathrm{Ni}-\mathrm{Cr}^{2,7,12,17,18} \mathrm{Cr}-\mathrm{Co},{ }^{6,11,17} \mathrm{Ag}-\mathrm{Pd} .{ }^{25}$

Different implant systems, such as Neodent, $2,5,18,24,26$ Conexão Sistemas de Prótese Ltda. 2,11 12,17,25 were employed. Neves et al. ${ }^{2}$ utilized the Biomet 3 i system, and Koke et al. ${ }^{6}$ used the Friadent $\mathrm{GmbH}$ system. Regarding the implant abutment connection, five studies evaluated the external connection, , 2,12,11,23,24 four studies evaluated the internal connection using mini pillar conical abutments, ${ }^{7,7718,25}$ and other studies did not report the implant type connection. ${ }^{5,6}$

\section{Soldering point technique}

The soldering point technique varied among the selected studies. Most of the included studies evaluated the welding technique regarding laser welding. 5,6,7,11,17,18,23,24,25 Certain studies have reported that the laser power ranged between $390 \mathrm{~V} / 9 \mathrm{~ms}$ and $300 \mathrm{~V} / 9 \mathrm{~ms}^{5,6,18,23,25}$ while other studies ${ }^{5,6,25}$ did not report the laser power used to weld the frameworks. In addition to the laser welding technique, two studies utilized a conventional welding technique, ${ }^{12,21}$ one study utilized the TIG technique $(36 \mathrm{~A} / 60 \mathrm{~ms}),{ }^{23}$ and one study utilized a brazing technique $\left(1,200^{\circ} \mathrm{C}-1,315^{\circ} \mathrm{C}\right) .^{2}$

In addition to the technique type, certain studies compared the effect of a cut in the soldering point and compared the cross-sectional form ${ }^{7,23}$ and/or diagonal form, $, 17,18,25$ while other studies did not report the soldering point position. $2,5,6,11,12$

\section{Measurement of marginal misfits}

To measure misfits, the majority of the studies used an optical microscope. ${ }^{5,7,7,18,23,25}$ A stereomicroscope, ${ }^{2}$ scanning electron microscopy, ${ }^{12}$ digital microscope, ${ }^{11}$ and microscope light ${ }^{6}$ were also employed. Only the study by Rodrigues et al. ${ }^{23}$ evaluated the internal misfit of the frameworks using X-ray microtomography scanning. Measurements at the interface between the implant/abutment were performed differently from the selected studies and are described in Table 2. Furthermore, certain studies ${ }^{5,7,17,18,25}$ evaluated the passive fit via the single screw test.

In addition to marginal misfits, further analyses, such as the screw torque test $\mathrm{t}^{23}$ and strain gauge, were conducted in one study. ${ }^{23}$

\section{Outcomes}

Among the selected studies, eight studies ${ }^{5,6,7,17,18,23,24,25}$ demonstrated the positive effect of welding on the adaptation of fixed implant frameworks. Two studies exhibited a positive effect on only one analyzed group, ${ }^{2,11}$ and only one study did not observe improvement when the soldering point was employed. ${ }^{12}$

\section{Meta-analysis}

Six studies were not considered in the meta-analysis because they presented insufficient data regarding the vertical marginal misfit described in terms of the mean and standard deviation. ${ }^{2,11,12,18}$ Thus, only seven studies were considered for the meta-analysis. ${ }^{5,6,7,17,23,24,25}$ In relation to the quantitative analysis, a relatively low value of marginal misfit for groups was observed with the welding technique compared with the one-piece cast technique ( $p$ < 0.00001; MD: -36.14; 95\%CI: -48.69 to -23.59) (Figure 2).

The randomized effect of the analysis was employed due to the high value of heterogeneity of the included studies $\left(I^{2}=96 \%\right)$, with a statistically significant value $(p<0,00001)$. In addition, the asymmetry of the included studies is observed using a funnel plot, which indicates the possibility of publication bias (Figure 3).

\section{Risk of bias}

The risk of bias analysis in the studies demonstrated a low risk of bias because the majority of the selected items were evaluated as a "yes," which increases the quality of the included studies. We highlight that the question regarding the follow-up period was evaluated as "not applicable" to the selected studies because all selected studies were considered in vitro (Table 3 ). 


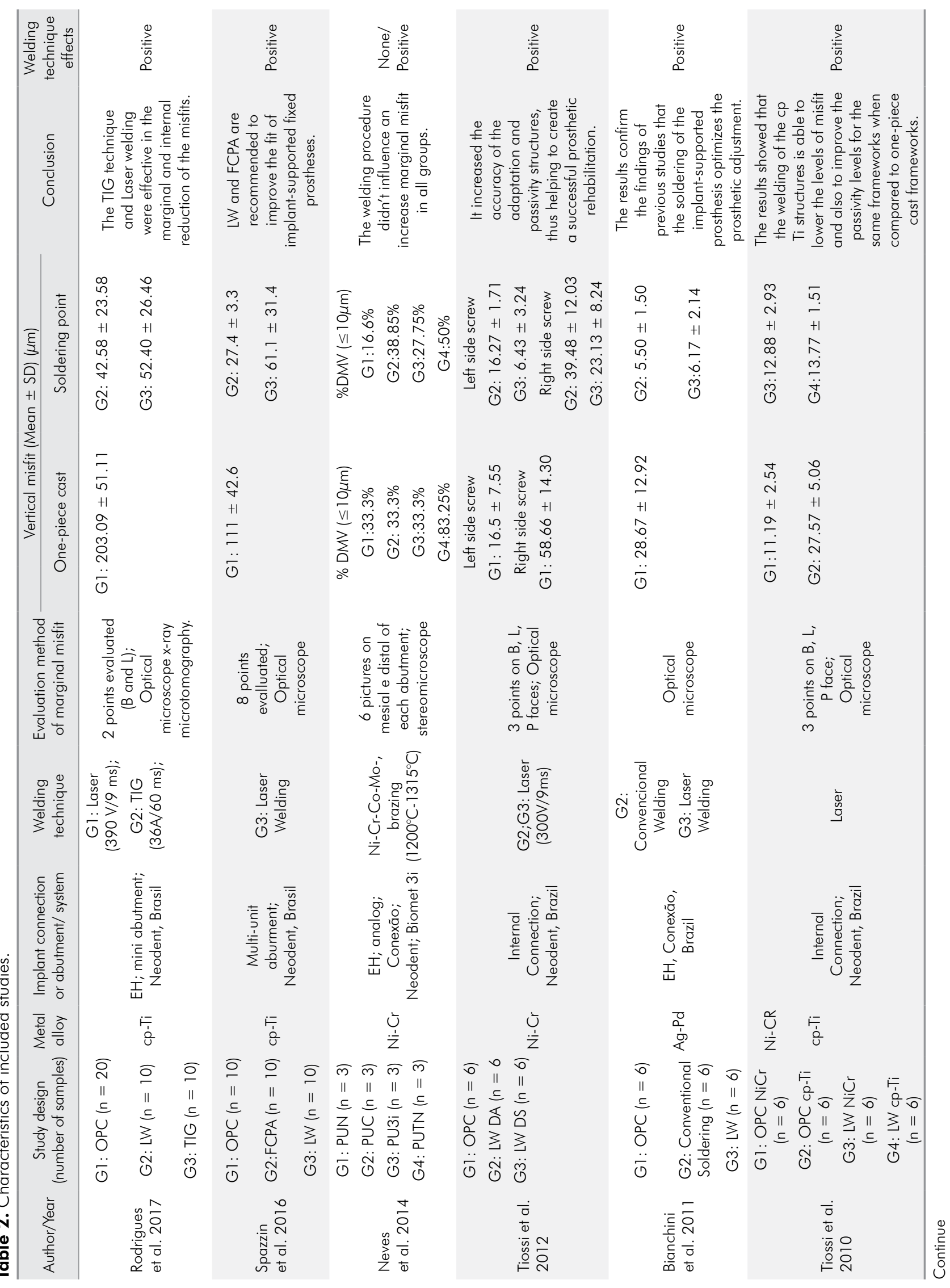




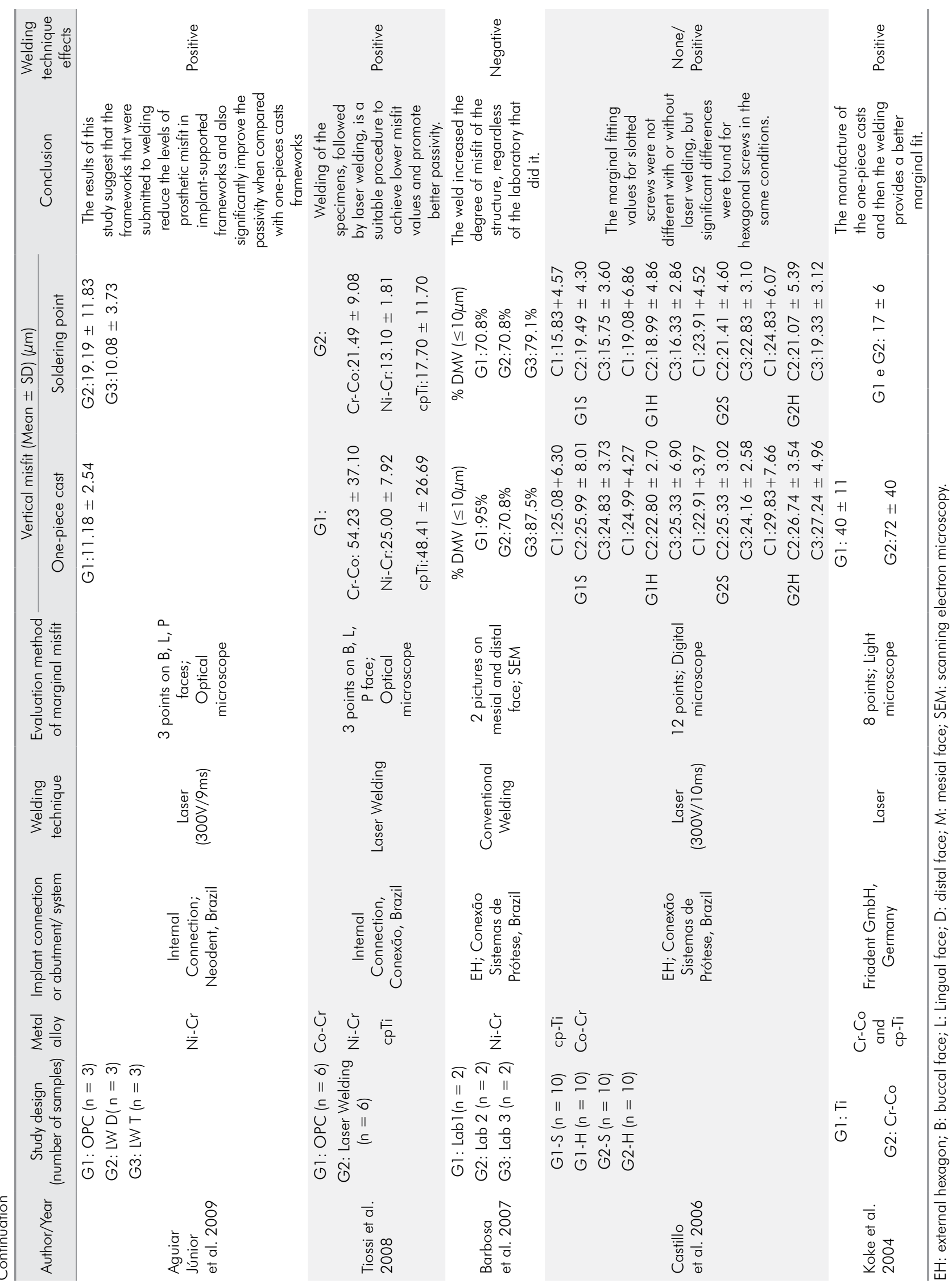




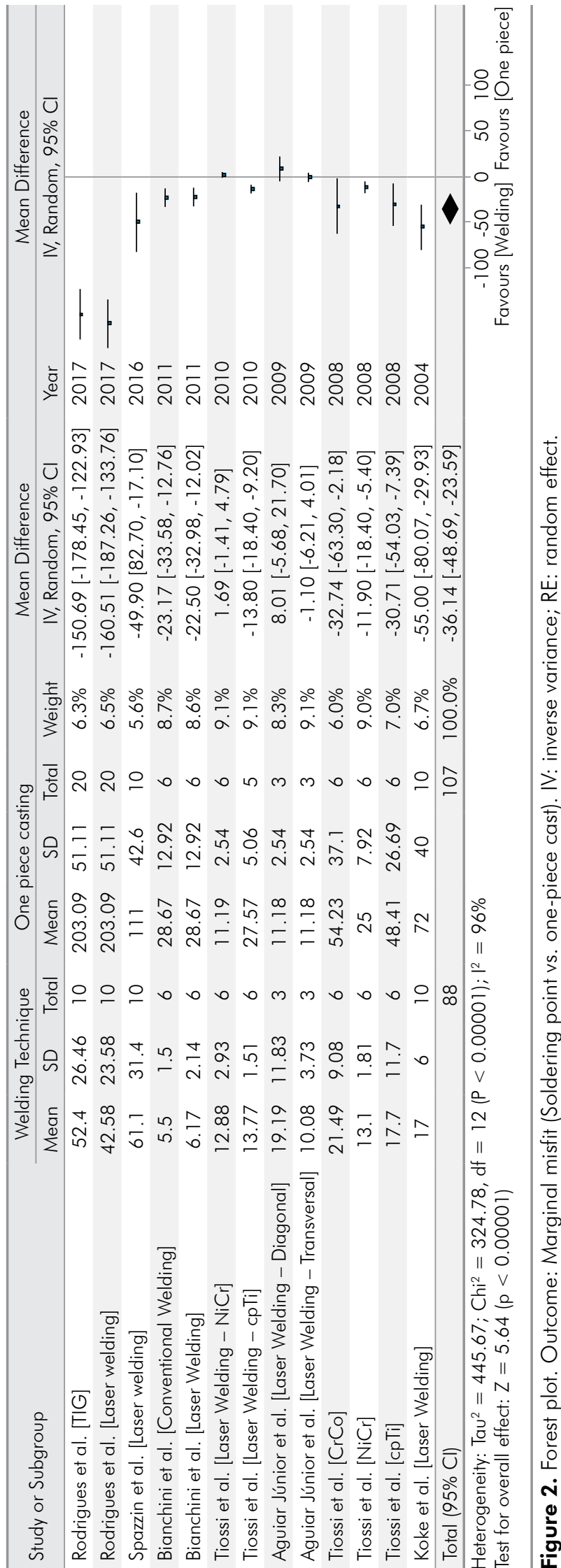

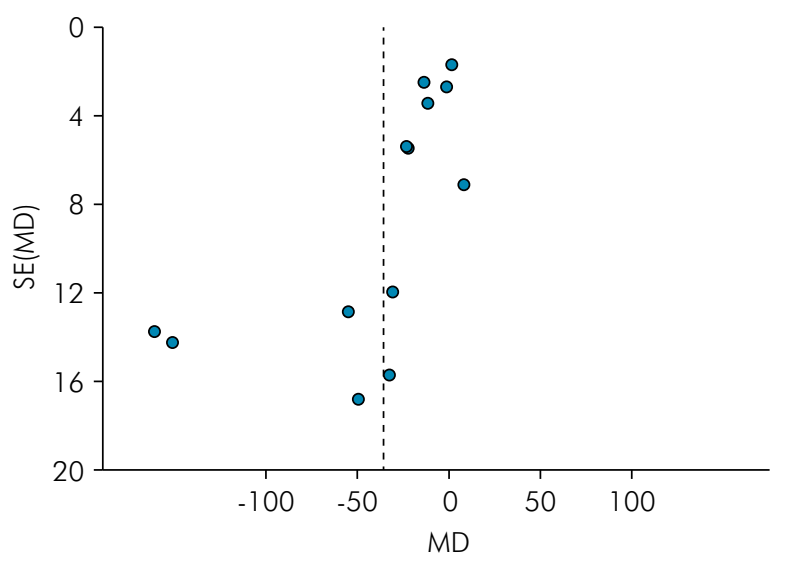

Figure 3. Funnel Plot. Heterogeneity analysis of included studies.

\section{Discussion}

The null hypothesis of this study affirms that no difference exists between a one-piece cast and the soldering point technique when a marginal fit was rejected because most of the selected studies presented a favorable characteristic for the soldering point technique and the quantitative results demonstrated a favorable significance for the welding frameworks ( $\mathrm{p}<0.00001$; MD: -36.14 ; 95\%CI: -48.69 to -23.59 ). These data agree with other studies. ${ }^{3,13,28,38}$ The misfit improvement in the majority of the frameworks after sectioning and welding may be related to the fact that this technique enables a reduction of distortions generated by the one-piece casting technique, which is caused by clinical and laboratorial steps, such as waxing, coating, and impression. . $^{2439,40}$

Most studies that observed favorable differences regarding the welding technique were conducted using the laser welding technique. ${ }^{5,6,7,18,23,25}$ Welding using the laser welding technique has advantages, such as easy application. ${ }^{5}$ Compared with the TIG technique ${ }^{24}$ or conventional technique, ${ }^{24}$ a laser has the advantage of using a minimal portion of the framework at the welding moment, which promotes a significant mechanical longevity of the framework. ${ }^{3}$

Further, two selected studies ${ }^{23,24}$ evaluated the laser welding technique and other methods of welding compared with a one-piece cast. In the study by Rodrigues et al., ${ }^{23}$ the misfit values after TIG welding $(52.4 \mu \mathrm{m})$ and laser welding $(42.58 \mu \mathrm{m})$ were similar 
Table 3. Risk of bias - JBI critical appraisal checklist for quase-experimental studies (non-randomized experimental studies).

\begin{tabular}{|c|c|c|c|c|c|c|c|c|c|}
\hline \multirow{2}{*}{\multicolumn{2}{|c|}{ Questions- JBI Critical appraisal checklist }} & \multicolumn{4}{|c|}{ Revisor 1} & \multicolumn{4}{|c|}{ Revisor 2} \\
\hline & & \multirow{2}{*}{$\begin{array}{c}\text { Yes } \\
11\end{array}$} & \multirow[t]{2}{*}{ No } & \multirow[t]{2}{*}{ Not clear } & \multirow[t]{2}{*}{ NR } & \multirow{2}{*}{$\begin{array}{c}\text { Yes } \\
11\end{array}$} & \multirow[t]{2}{*}{ No } & \multirow[t]{2}{*}{ Not clear } & \multirow[t]{2}{*}{ NR } \\
\hline 1 & $\begin{array}{l}\text { Is it clear in the study what is the 'cause' and what is the 'effect' } \\
\text { (i.e. there is no confusion about which variable comes first)? }\end{array}$ & & & & & & & & \\
\hline 2 & Were the participants included in any comparisons similar? & 11 & & & & 11 & & & \\
\hline 3 & $\begin{array}{l}\text { Were the participants included in any comparisons receiving similar } \\
\text { treatment/care, other than the exposure or intervention of interest? }\end{array}$ & 9 & 2 & & & 9 & 2 & & \\
\hline 4 & Was there a control group? & 9 & 2 & & & 9 & 2 & & \\
\hline 5 & $\begin{array}{l}\text { Were there multiple measurements of the outcome both pre and post } \\
\text { the intervention/exposure? }\end{array}$ & 11 & & & & 11 & & & \\
\hline 6 & $\begin{array}{l}\text { Was follow up complete and if not, were differences between groups } \\
\text { in terms of their follow up adequately described and analyzed? }\end{array}$ & & & & 11 & & & & 11 \\
\hline 7 & $\begin{array}{l}\text { Were the outcomes of participants included in any comparisons } \\
\text { measured in the same way? }\end{array}$ & 11 & & & & 11 & & & \\
\hline 8 & Were outcomes measured in a reliable way? & 11 & & & & 11 & & & \\
\hline 9 & Was appropriate statistical analysis used? & 9 & 2 & & & 9 & 2 & & \\
\hline
\end{tabular}

with respect to soldering point techniques. Thus, the welding method does not seem to exhibit a considerable effect on the values of vertical misfit since any method will decrease the misfit compared with a one-piece cast.

A single study among the selected ${ }^{12}$ few studies reported the negative effect of the conventional welding technique. ${ }^{12}$ In this study, misfit values $\leq 10$ $\mu \mathrm{m}$ occurred on an average of $84.43 \%$ (70.8\%-95\%) of the frameworks manufactured in a one-piece cast and averaged $73.56 \%(70.8 \%-79.1 \%)$ for soldering point frameworks. A justification of these results by the authors is that conventional welding may cause distortions during manufacturing, which increases the misfit levels. However, another study ${ }^{24}$ observed a positive effect of the conventional welding technique compared with the one-piece cast technique. ${ }^{24}$ The justification is the use of noble alloys, where the material experiences less distortion in one-piece cast frameworks and improves when the soldering point technique is used. ${ }^{41}$ Other studies included in this review ${ }^{6,7,11,17,18,24,26}$ evaluated non-noble alloys ( $\mathrm{Ni}-\mathrm{Cr}$, $\mathrm{Cr}-\mathrm{Co}, \mathrm{cpTi}$ ) and opted for the use of a laser welding technique to obtain better precision when adapted.

Moreover, certain studies have not verified the effect of the welding technique compared with the one-piece cast. ${ }^{2,11}$ In the study conducted by Neves et al. ${ }^{2}$, the absence of a difference in the brazing type compared with one-piece casting may be related to the brazing technique, which is executed to construct the framework ${ }^{13,40}$ and enables considerable distortion possibilities in the same manner as the one-piece cast confection. Castilho et al. ${ }^{11}$ report that this finding may be related to the effect of the different screws with respect to the type of cylinder. The screws with grooves in this study are composed of gold, with a high elastic modulus and consequent deformation of their threads at the moment of load application, which may have hindered a better fit of the implant infrastructure. ${ }^{11,23}$

The cut type used for welding is another factor that can affect the results. Certain studies conducted the cutting of the soldering point in diagonal and transverse forms $\mathrm{s}^{7,25}$ and report that a diagonal cut will affect a relatively small amount of material in the region to be welded, which produces relatively low structure distortions when the metal undergoes cold contractions.

The studies selected in this review observed averages for framework misfits manufactured in a one-piece cast that varied in the range 11.18-203 $\mu \mathrm{m}$. For frameworks manufactured via welding, the values were in the range 10.8-61.1 $\mu \mathrm{m}$. Therefore, the lowest values observed in the infrastructures manufactured via the soldering point technique were highlighted, which indicates its benefit regarding the marginal adaptation of fixed implant prosthesis frameworks. 
The results observed in this systematic review should be interpreted with caution, because a range of factors that can affect the final results of the work were observed. A high heterogeneity in the meta-analysis may be justified because the data are related to in vitro studies; a lack of standardization due to the included studies may affect the increase in this pattern. In addition, the studies indicated limitations regarding the standardization of the techniques used to construct the frameworks in a one-piece cast and the soldering point technique. Moreover, the method of evaluation of the marginal misfit varied between the equipment and the evaluated points. Regarding the framework size, no standardization existed, which influences the effectiveness of the welding. ${ }^{24}$

Within the observed limitations, this systematic review of in vitro studies attempted to evaluate the marginal misfit of the fixed prostheses with implanted-supported frameworks manufactured in a one-piece cast compared with welding techniques, which indicated better results regarding the vertical misfit for frameworks manufactured using the welding technique. However, additional studies are required to evaluate the biomechanical and biological behaviors of these frameworks, as well as the effect of the soldering point on the adaptation of implanted-supported prostheses.

\section{Conclusions}

Within the limitations of this study and regarding the heterogeneity of the samples, we can conclude that the soldering point technique is effective for obtaining relatively low values of marginal misfit, with laser welding as the most effective technique. However, additional studies are recommended due to the heterogeneity of different variables (alloys, connection, and misfit evaluation) in the included studies.

\section{Acknowledgement}

Research Foundation of the State of São Paulo FAPESP: 11/19150-7.

\section{References}

1. Yannikakis S, Prombonas A. Improving the fit of implant prosthetics: an in vitro study. Int J Oral Maxillofac Implants. 2013 Jan-Feb;28(1):126-34. https://doi.org/10.11607/jomi.2346

2. Neves FD, Elias GA, Silva-Neto JP, Dantas LCM, Mota AS, Fernandes Neto AJ. Comparison of implant-abutment interface misfits after casting and soldering procedures. J Oral Implantol. 2014 Apr;40(2):129-35. https://doi.org/10.1563/AAID-JOI-D-11-00070

3. Abduo J, Lyons K, Bennani V, Waddell N, Swain M. Fit of screw-retained fixed implant frameworks fabricated by different methods: a systematic review. Int J Prosthodont. 2011 May-Jun;24(3):207-20.

4. Lencioni KA, Macedo AP, Rodrigues RCS, Ribeiro RF, Almeida RP. Photoelastic comparison of as-cast and laser-welded implant frameworks. J Prosthet Dent. 2015 Nov;114(5):652-9. https://doi.org/10.1016/i.prosdent.2015.06.005

5. Spazzin AO, Bacchi A, Trevisani A, Farina AP, Santos MB. Fit analysis of different framework fabrication techniques for implant-supported partial prostheses. Int J Prosthodont. 2016 Jul-Aug;29(4):351-3. https://doi.org/10.11607/ijp.4542

6. Koke U, Wolf A, Lenz P, Gilde H. In vitro investigation of marginal accuracy of implant-supported screw-retained partial dentures. J Oral Rehabil. 2004 May;31(5):477-82. https://doi.org/10.1111/j.1365-2842.2004.01271.x

7. Aguiar FA Jr, Tiossi R, Rodrigues RC, Mattos MG, Ribeiro RF. An alternative section method for casting and posterior laser welding of metallic frameworks for an implant-supported prosthesis. J Prosthodont. 2009 Apr;18(3):230-4. https://doi.org/10.1111/j.1532-849X.2008.00405.x

8. Ortorp A, Jemt T, Bäck T, Jälevik T. Comparisons of precision of fit between cast and CNC-milled titanium implant frameworks for the edentulous mandible. Int J Prosthodont. 2003 Mar-Apr;16(2):194-200.

9. Al-Fadda SA, Zarb GA, Finer Y. A comparison of the accuracy of fit of 2 methods for fabricating implant-prosthodontic frameworks. Int J Prosthodont. 2007 Mar-Apr;20(2):125-31.

10. Silva TB, Nobilo MAA, Pessanha Henriques GE, Mesquita MF, Guimaraes MB. Influence of laser-welding and electroerosion on passive fit of implant-supported prosthesis. Stomatologija. 2008;10(3):96-100.

11. Castilio D, Pedreira AP, Rossetti PH, Rossetti LM, Bonachela WC. The influence of screw type, alloy and cylinder position on the marginal fit of implant frameworks before and after laser welding. J Appl Oral Sci. 2006 Apr;14(2):77-81. https://doi.org/10.1590/S1678-77572006000200003 
12. Barbosa GA, Simamoto Júnior PC, Fernandes Neto AJ, Mattos MG, Neves FD. Prosthetic laboratory influence on the vertical misfit at the implant/UCLA abutment interface. Braz Dent J. 2007;18(2):139-43. https://doi.org/10.1590/S0103-64402007000200010

13. Barbi FC, Camarini ET, Silva RS, Endo EH, Pereira JR. Comparative analysis of different joining techniques to improve the passive fit of cobalt-chromium superstructures. J Prosthet Dent. 2012 Dec;108(6):377-85. https://doi.org/10.1016/S0022-3913(12)60196-6

14. Weinreich TD. Estudo da soldagem a laser em próteses odontológicas. Belo Horizonte; 2011.

15. Peçanha MM. Estudo comparativo da desadaptação marginal de infraestruturas metálicas para próteses sobre implantes, após soldagem a laser e soldagem convencional [dissertation]. Centro de Ciências da Saúde, Universidade Federal do Espírito Santo, Vitória, ES, 2009.

16. Silva J. Avaliação da resistência flexural entre diferentes métodos de soldagem: Chama Direta - TIG- Laser [dissertation]. Faculdade de Odontologia de Ribeirão Preto, Universidade de São Paulo, 2007.

17. Tiossi R, Rodrigues RC, Mattos MG, Ribeiro RF. Comparative analysis of the fit of 3-unit implant-supported frameworks cast in nickel-chromium and cobalt-chromium alloys and commercially pure titanium after casting, laser welding, and simulated porcelain firings. Int J Prosthodont. 2008 Mar-Apr;21(2):121-3.

18. Tiossi R, Falcão-Filho HB, Aguiar Junior FA, Rodrigues RC, Mattos MG, Ribeiro RF. Prosthetic misfit of implant-supported prosthesis obtained by an alternative section method. J Adv Prosthodont. 2012 May;4(2):89-92. https://doi.org/10.4047/jap.2012.4.2.89

19. Moher D, Liberati A, Tetzlaff J, Altman DG. Preferred reporting items for systematic reviews and meta-analyses: the PRISMA statement. BMJ. 2009 Jul;339 jul21 1:b2535. https://doi.org/10.1136/bmi.b2535

20. Lemos CA, Ferro-Alves ML, Okamoto R, Mendonça MR, Pellizzer EP. Short dental implants versus standard dental implants placed in the posterior jaws: A systematic review and meta-analysis. J Dent. 2016 Apr;47:8-17. https://doi.org/10.1016/i.jdent.2016.01.005

21. Lemos CA, Verri FR, Batista VE, Santiago Júnior JF, Mello CC, Pellizzer EP. Complete overdentures retained by mini implants: A systematic review. J Dent. 2017 Feb;57:4-13. https://doi.org/10.1016/i.jdent.2016.11.009

22. Lemos CA, Batista VES, Almeida DA, Santiago Júnior JF, Verri FR, Pellizzer EP. Evaluation of cement-retained versus screw-retained implant-supported restorations for marginal bone loss: a systematic review and meta-analysis. J Prosthet Dent. 2016 Apr;115(4):419-27. https://doi.org/10.1016/i.prosdent.2015.08.026

23. Rodrigues SA, Presotto AG, Barão VA, Consani RL, Nóbilo MA, Mesquita MF. The role of welding techniques in the biomechanical behavior of implant-supported prostheses. Mater Sci Eng C. 2017 Sep;78:435-42. https://doi.org/10.1016/i.msec.2017.04.090

24. Bianchini MA, Souza JG, Souza DC, Magini RS, Benfatti CA, Cardoso AC. Are sectioning and soldering of short-span implant-supported prostheses necessary procedures? Acta Odontol Latinoam. 2011;24(1):21-8.

25. Tiossi R, Falcão-Filho H, Aguiar Júnior FA, Rodrigues RC, Mattos MG, Ribeiro RF. Modified section method for laser-welding of ill-fitting cp Ti and $\mathrm{Ni}$-Cr alloy one-piece cast implant-supported frameworks. J Oral Rehabil. 2010 May;37(5):359-63. https://doi.org/10.1111/j.1365-2842.2010.02063.x

26. Clelland NL, Carr AB, Gilat A. Comparison of strains transferred to a bone simulant between as-cast and postsoldered implant frameworks for a five-implant-supported fixed prosthesis. J Prosthodont. 1996 Sep;5(3):193-200. https://doi.org/10.1111/j.1532-849X.1996.tb00296.x

27. Zervas PJ, Papazoglou E, Beck FM, Carr AB. Distortion of three-unit implant frameworks during casting, soldering, and simulated porcelain firings. J Prosthodont. 1999 Sep;8(3):171-9. https://doi.org/10.1111/j.1532-849X.1999.tb00032.x

28. Alvarez A, Lafita P, Llanos H, Gago A, Brizuela A, Ellacuria JJ. A comparison of two soldering techniques on the misfit of bar-retained implant-supported overdentures. J Prosthodont. 2014 Feb;23(2):163-70. https://doi.org/10.1111/jopr.12083

29. Costa EM, Hoçoya LS, Bottino MA. The fitness of copings constructed over UCLA abutments and the implant, constructed by different techniques: casting and casting with laser welding. J Appl Oral Sci. 2004 Dec;12(4):349-54. https://doi.org/10.1590/S1678-77572004000400018

30. Riedy SJ, Lang BR, Lang BE. Fit of implant frameworks fabricated by different techniques. J Prosthet Dent. 1997 Dec;78(6):596-604. https://doi.org/10.1016/S0022-3913(97)70011-8

31. Rubenstein JE, Ma T. Comparison of interface relationships between implant components for laser-welded titanium frameworks and standard cast frameworks. Int J Oral Maxillofac Implants. 1999 Jul-Aug;14(4):491-5.

32. Silveira-Júnior CD, Neves FD, Fernandes-Neto AJ, Prado CJ, Simamoto-Júnior PC. Influence of different tightening forces before laser welding to the implant/framework fit. J Prosthodont. 2009 Jun;18(4):337-41. https://doi.org/10.1111/i.1532-849X.2008.00418.x

33. Sousa SA, Nobilo MAA, Henriques GE, Mesquita MF. Passive fit of frameworks in titanium and palladium-silver alloy submitted the laser welding. J Oral Rehabil. 2008 Feb;35(2):123-7. https://doi.org/10.1111/j.1365-2842.2003.01218.x

34. Byrne G, Laub LW, Hu JY, Land MF. The fit of fixed partial dentures joined by infrared soldering. J Prosthet Dent. 1992 Oct;68(4):591-6. https://doi.org/10.1016/0022-3913(92)90371-G

35. Jei JB, Mohan J. Comparative evaluation of marginal accuracy of a cast fixed partial denture compared to soldered fixed partial denture made of two different base metal alloys and casting techniques: an in vitro study. J Indian Prosthodont Soc. 2014 Mar;14(1):104-9. https://doi.org/10.1007/s13191-013-0286-2

36. Evans DB. Correcting the fit of implant-retained restorations by electric discharge machining. J Prosthet Dent. 1997 Feb;77(2):212-5. https://doi.org/10.1016/S0022-3913(97)70238-5 
Systematic review and meta-analysis of welding procedures in one-piece cast implant-supported frameworks

37. Landis JR, Koch GG. The measurement of observer agreement for categorical data. Biometrics. 1977 Mar;33(1):159-74. https://doi.org/10.2307/2529310

38. Abduo J, Bennani V, Waddell N, Lyons K, Swain M. Assessing the fit of implant fixed prostheses: a critical review. Int J Oral Maxillofac Implants. 2010 May-Jun;25(3):506-15.

39. Pantoja JM, Farina AP, Vaz LG, Consani RL, Nóbilo MA, Mesquita MF. Fatigue strength: effect of welding type and joint design executed in Ti-6Al-4V structures. Gerodontology. 2012 Jun;29(2):e1005-10. https://doi.org/10.1111/j.1741-2358.2011.00598.x

40. Romero GG, Engelmeier R, Powers JM, Canterbury AA. Accuracy of three corrective techniques for implant bar fabrication. J Prosthet Dent. 2000 Dec;84(6):602-7. https://doi.org/10.1067/mpr.2000.111494

41. França DG, Morais MH, Neves FD, Carreiro AF, Barbosa GA. Precision fit of screw-retained implant-supported fixed dental prostheses fabricated by CAD/CAM, copy-milling, and conventional methods. Int J Oral Maxillofac Implants. 2017 May/Jun;32(3):507-13. https://doi.org/10.11607/jomi.5023

42. Gehrke SA, Delgado-Ruiz RA, Frutos JCP, Prados-Privado M, Dedavid BA, Granero Marín JM, et al. Misfit of three different implant-abutment connections before and after cyclic load application: an in vitro study. Int J Oral Maxillofac Implants. 2017 Jul/Aug;32(4):822-9. https://doi.org/10.11607/jomi.5629 